Bol. Acad. peru. leng. 51. 2011 (213-220)

\title{
VARGAS LLOSA DE NUEVO EN SAN MARCOS
}

Carlos Eduardo Zavaleta $†$

Academia Peruana de la Lengua

Fecha de recepción:

$10 / 12 / 2010$

Fecha de aceptación:

$25 / 02 / 2011$

Señor rector de la Universidad Nacional Mayor de San Marcos, señores decanos de las distintas facultades, doctor Mario Vargas Llosa, entrañable amigo de juventud, señores y señoras catedráticos, señores y señoras, queridos alumnos y alumnas.

Todos, todos aquí en San Marcos estamos de fiesta. Ha vuelto una vez más al claustro el antiguo alumno, el que fuera profesor auxiliar y bachiller, y luego nuestro Dr. honoris causa por excelencia, el profesor selecto e invitado por innumerables universidades, y sobre todo desde su juventud un singularísimo y múltiple escritor, ahora ya reconocido y honrado con las mejores galas culturales que tiene este siglo XXI en el mundo. Está de nuevo y de veras aquí, quien provoca merecidamente nuestro júbilo.

En cuanto él supo oficialmente que había ganado el Premio Nóbel, confesó: "Yo soy el Perú". ¡Qué doble orgullo para San Marcos!, pues él 
había declarado mucho antes que sólo comprendió y conoció a todo el Perú cuando entró a estudiar en San Marcos ¡Bienvenido sea el antiguo alumno pugnaz y batallador, el ahora maestro y experto en revelar a sus discípulos las entrañas de la ficción, al mismo tiempo que sigue, a través de brillantes ensayos y de su incesante actividad periodística, sigue siendo un gran forjador de opiniones humanísticas, políticas y democráticas en el mundo! Frente a este despliegue de bagaje cultural, educativo y artístico, ahora sólo cabe celebrar que, lo que parecía no existir, la llamada justicia literaria, la esencia más difícil, pues sí, existe, y ha llegado hasta él y asimismo hasta nosotros.

Lo que él ha cumplido es toda una hazaña. Por supuesto que sólo alguno, o ninguno (pues ya estamos casi desapareciendo), de sus colegas en el menester literario, desde el primer momento, había o habría soñado con este increíble desenlace, producido casi en el mismo borde de las cosas. ¡Pero, sí, es verdad, ha sucedido!

Lo que él ha cumplido es, repito, toda una hazaña. Mirando atrás, sí hemos tenido, como otras generaciones, unas líneas de sombra (frase descriptiva y feliz del gran novelista Joseph Conrad), y otras líneas felizmente de luz y esperanza. Creo que el mundo que veíamos opaco en nuestra juventud cambió para el Perú, y de algún modo para todos los países, cuando, en 1945, acabó la Segunda Guerra Mundial (y que ojalá ésa haya sido la última en existir, pues creo que la humanidad entera ya no permitiría otra). Sí, en ese 1945, para nuestra suerte, coincidió esa luz de esperanza cuando al fin se unió el destino del Perú con el destino histórico del mundo, y eso trajo consigo, desde abril y mayo en adelante, la victoria asimismo interna de la liberación, el humanismo, y así creíamos que nos salvaríamos del último déspota del país. ¡Qué coincidencia tan enorme, tan providencial! Estuvimos casi felices desde el año previo, cuando sucedió la liberación de París y la festejamos con una manifestación de colegiales y estudiantes hacia el local de la Alianza Francesa, en la esquina de Wilson con Uruguay; y más todavía, a partir de abril y mayo del 45, cuando la rendición incondicional de Alemania, y cuando hubo un inmenso retroceso, la terrible noticia de las pruebas y del lanzamiento real de la bomba atómica, y por fin las elecciones libres 
en el Perú y cuando nos dijimos, el 28 de julio, que ya éramos otra clase de país...

Pero nos atropellamos a nosotros mismos, la primavera peruana sólo duró tres años, y de vuelta caímos en una insensata lucha intestina entre victoriosos (algo horrendo, y a veces muy peruano), y desde entonces se nos reabrió una larga línea de sombra que, con un pequeño intervalo, quizá solamente acabó en 1980.

De esa época de extrañas alternancias entre una solitaria línea de esperanza, en medio de las sombras, de ahí nació nuestra generación literaria. Los poetas formaban ya un grupo desde 1944; los narradores lo hicimos desde 1946 y 1948 en adelante, publicando más de una veintena de libros de cuentos y menos de esa cantidad en novelas (varias de ellas novelas cortas), y pudimos asimismo publicar revistas propias y pusimos de moda las presentaciones y lecturas de textos inéditos en público. De esa gran actividad surgió, vivaz y pujante, la formación juvenil de Vargas Llosa, quien, de pronto, hacia 1955, tenía ya dos columnas periodísticas, donde entrevistaba a todo aquel que hubiese publicado un libro de cuentos o una novela, y una de esas columnas aparecía en "El Dominical"; de El Comercio, y otra, sobre pensadores e intelectuales, en Cultura Peruana, la revista de La Crónica.

(Ahora, entre paréntesis, diré lo que faltaba, había que subrayar también otra fecha importantísima en esta evolución. En 1951, en medio de la dictadura, San Marcos, y específicamente nuestro maestro el historiador Raúl Porras Barrenechea, convocaron al Primer Congreso Internacional de Peruanistas, y ésa fue otra línea de luz y esperanza. Jamás antes habíamos visto en nuestros claustros a tantos escritores y sabios, y filósofos de todo el mundo, dialogando con nuestros maestros habituales. No olvido, por ejemplo, a Alberto Wagner de Reyna, filósofo y diplomático, presentando sus propias traducciones de Heidegger, ni tampoco la firmeza del grupo francés dedicado al filósofo Bergson, o la consolidación de vínculos científicos del Perú con Alemania, o el rico tema de los viajeros ingleses y norteamericanos al Perú, iniciado por Estuardo Núñez, o las discretas sutilezas que separaban a intelectuales 
ingleses, italianos o eslavos. En fin, recordamos asimismo las exquisitas polémicas entre Aurelio Miró Quesada y Raúl Porras, sin duda sobre el Inca Garcilaso, o entre el antropólogo francés Paul Rivet y el mismo anfitrión peruano). Aquí cierro el paréntesis.

Hacia 1956 aparece el primer cuento de Vargas Llosa. Pero cuando él tuvo ya listo su primer libro de cuentos e incluso cuando ganó con él un premio literario internacional, en 1959, supo pensar fríamente en si le convenía o no ese género narrativo, y luego optó sabiamente por no practicarlo más, y eligió la novela maciza y nos adelantó a todos en el nuevo género. Sí, escogió un género que nosotros no podíamos cultivar aquí, pues carecíamos de editoriales de verdad, y él lo decidió así en sus viajes de becario a París y Madrid, y cuando, ya sin beca alguna, se sobrepuso a todas las dificultades, siguió escribiendo incluso cuando tuvo problemas de publicar La ciudad y los perros por la censura española. Así, casi lanzado al vacío, así se expuso y tuvo una admirable suerte que él mismo reconoce hasta hoy. Pero no sólo suerte, sino enormes merecimientos indudables, valor y coraje, que deben servir de ejemplo a todos nosotros, alumnos y profesores.

Lo ganó, pues, la novela larga, ese arma poderosa y formidable, ese género maternal por excelencia, que lo engloba todo en su seno, todo cae bien en ella, la historia, la sociología, la psicología, la filosofía, la epopeya moderna, incluso la poesía, he ahí un género que es la sabiduría selecta y continua para librar o sólo entretener al hombre en sus viejísimas sombras.

Yo recuerdo esa entrevista que con él hicimos para su columna de narradores, de El Comercio, en 1955. Puesto que teníamos ya en la cabeza a Dostoievski y a Tolstoi, hablamos de los otros escritores en boga, de James Joyce y el Ulises, de T.S. Eliot y de Ezra Pound (a quienes habíamos empezado a traducir en Lima), y asimismo, del inevitable William Faulkner, sobre quien yo preparaba dos tesis universitarias, y también de John Dos Passos, el de los contrapuntos estilísticos y contraste de personajes, dentro de una gran ciudad, como Nueva York, por ejemplo. Y claro que sí, también de los notables existencialistas franceses y de 
los últimos autores italianos. Estábamos encandilados por todos ellos. Pero nuestro diálogo brotaba desde Lima, en Lima, en nuestra ciudad que nos parecía pequeña y opresiva, aunque sin duda empezábamos ya a entender con qué clase de monstruos nos habíamos metido.

Sí, en ese grupo de eminentes escritores del mundo estaban los mejores ejemplos a seguir por los jóvenes. Vargas Llosa los admiraría siempre como maestros, pero pronto elegiría un camino propio, libre, vecino del otro, pero distinto, el camino de la experimentación estilística y del contrapunto de personajes y psicologías, exponiéndolos en espacios sucesivos que le permitirían ofrecer la vida pujante y juvenil, las carencias y peculiaridades de nuestra cultura latinoamericana.

¡Vaya admirable camino el suyo, que en sólo seis años, de 1963 a 1969, le llevó desde La ciudad y los perros, desde el círculo de una institución cerrada en una sociedad informe, que cae fácilmente en el caos, y que vuelve a ser "ordenada" a voluntad por el transgresor de turno; desde ese modelo de opresiones, abusos y rebeldías aun juveniles, hasta $\mathrm{La}$ casa verde, en que todo el supuesto vacío amazónico de nuestro inmenso mapa, se puebla al fin de pensamientos, monólogos, descripciones y diálogos, que ofrecen modelos extraños de vida, historias y aun leyendas que acompañan al hombre en esa inmensa soledad. Y así también el autor viajó desde el delicioso invento estilístico de Los cachorros (1967), en que él crea un "narrador plural", crea la voz conjunta de un barrio limeño que cuenta la historia de Cuéllar, y nos reordena la oración castellana con sujetos, verbos y predicados cambiantes para deleite, gozo y faena del nuevo lector cómplice. Y no sólo eso, sino que avanzó hacia Conversación en la catedral, (1969) (¿Cómo olvidar el famoso título de Asesinato en la catedral, de Eliot?), y aquí Vargas Llosa crea el gran modelo de contrapuntos y voces, de posiciones vitales, éticas y aun políticas, donde también el hombre común y el joven aspirante son los mejores trasmisores de la historia.

Sólo hemos llegado a 1969, a esas primeras cumbres de su creación, y ya debemos reconocer que es imposible, en una sesión, 
remontar siquiera los inicios de su obra, que, sin embargo, en sí mismos, constituyen la culminación de su gran primer ciclo, el que se cierra con La guerra del fin del mundo (1982), novela ya clásica y que mereció en Lima una mayúscula presentación en el Hotel Bolívar, nada menos que con dos oradores famosos, uno de ellos un Presidente de la talla de Fernando Belaúnde, y otro un líder político, pero culto, repito, político, pero culto, como Luis Alberto Sánchez, quien fue por tres veces Rector de S.M. Y así, en esa vasta novela, Vargas Llosa nos ofrece otra espléndida virtud, la de armar estructuras literarias que ofrecen complejos temas que, o bien son peruanísimos desde el comienzo, o bien lo son en su esencia, desarrollo o conclusión. Aquí, estructura y tema son un ejemplo de que alguna inmensa veta faltaba por explorar, la del gigantesco Brasil y su huraña vecindad con el Perú. He aquí una ficción que el lector coloca junto a otra ficción preexistente, de un famoso autor brasileño. Bella costumbre ésta de enlazar ficciones, como las enlazaban los grandes poetas isabelinos Ben Jonson, Christopher Marlowe o William Shakespeare, quienes solían ampliar y repetir temas y personajes cambiantes, o como hizo el propio Cervantes con el Quijote, donde la ficción se redobla, duplica o triplica en un admirable juego de espejos.

Siguiendo esta misma veta, de vínculos peruanistas, surgen por ejemplo notables personajes reales e históricos, como la ensayista Flora Tristán y el pintor Paul Gauguin (dos agudas mentes del siglo $\mathrm{XIX),} \mathrm{quienes} \mathrm{viven,} \mathrm{viajan} \mathrm{o} \mathrm{recuerdan} \mathrm{nuestro} \mathrm{país,} \mathrm{y} \mathrm{extraen} \mathrm{aquí}$ conclusiones válidas para el pensamiento o el arte mundial. Así lo vemos en El paraíso en la otra esquina.

En otro riquísimo género, el de ensayos, Vargas Llosa confirma su calidad de lector, crítico y novelista practicante, y nos da no sólo juicios perdurables sobre gran parte de las novelas modernas del siglo XX, sin olvidar la producción latinoamericana, sino también confirma su calidad de maestro, erudito y analista de la propia ficción, en sus admirables Cartas a un novelista (1997), destinadas a nuestros alumnos y maestros universitarios, en la vastedad de la lengua española. 
Labor semejante cumplirá al llevar el tema político de la dictadura y del abuso de derechos humanos más allá de nuestras fronteras. Eso lo vemos bien en La fiesta del chivo (2000), pues la dictadura es un tema vivo y ambulante, latinoamericano y peruano, y aun mundial, y nace justamente en las primeras novelas de nuestro autor.

Y ahora, con la última novela, El sueño del celta (2010), en medio de las atrocidades del Congo (por obra de la cultísima Europa), Vargas Llosa ha hallado asimismo el enlace con el Perú, el vínculo humano y artístico indudable, y así vemos los durísimos cuadros de la corrupción en nuestra Amazonía, pues el héroe Roger Casement, reaparece aquí, investigando y señalando culpables en esa extrañísima mezcla de hombres y esclavos, viviendo en un increíble infierno medieval. $O$ sea que algunas lacras de la Edad Media nos llegaron aquí hasta bien entrado el siglo XX.

En fin, de todo lo dicho rápidamente sobre sus inicios, y sobre otras épocas de su obra, uno podría suponer que solo hemos tratado de un escritor múltiple, de un intelectual, de un pensador a quien incluso le interesa moldear las sociedades, empezando por la latinoamericana. Pero no le pongamos ningún molde dramático, serio, adusto, ni menos trágico; él nos ha dado pruebas de su enorme versatilidad, inclusive crea argumentos satíricos, burlones y aun cómicos (recordemos Pantaleón y las visitadoras (1973) y La tía Julia y el escribidor (1977)), de los cuales sale bien librado, o de esa confrontación de valores clásicos y aun de la tragedia griega versus el mundo andino (recordad Lituma en los Andes) (1993). Estamos, más bien, ante un pensador que es al mismo tiempo un experimentador de estructuras, estilos, ideas, una increíble mezcla de actitudes como las de por ejemplo, en su tiempo, David Herbert Lawrence, Aldous Huxley y André Malraux juntos, imagínense qué riqueza y al mismo tiempo qué complejidad. Creo que por los años 30s y 40 s se hablaba de autores lógicos frente a los autores mágicos. En fin, no me atreveré a calificar a un maestro de maestros, cuya obra sigue por suerte vigente y poderosa.

Además, desde su vasta tesis doctoral sobre García Márquez y sus plausibles ensayos sobre Flaubert, Víctor Hugo y Onetti, Vargas Llosa va 
en camino de construir toda una biblioteca crítica sobre grandes maestros novelísticos del mundo. ¿Qué otro se ha propuesto una meta así?

Voy a concluir. Mil perdones por esta apretadísima y peligrosa síntesis, debido en verdad a mi mala salud y a mi poca resistencia, y sólo debo añadir que la novela El sueño del celta, que quizá haya sido el trigger, el detonante para borrar las últimas y curiosas dudas de la Academia Sueca, es en verdad no sólo una gran novela de ideas y aventuras, digo, de hechos y huesos fidedignos, como diría Vallejo, sino que es también un espléndido homenaje literario a toda Irlanda, a Irlanda del Norte, que por fin goza de alguna paz, ahora mismo, pero de verdad, goza de paz luego de siglos de su histórica e increíble lucha con Gran Bretaña, y es también un homenaje a la otra, a la República de Irlanda, libre ya por fin desde 1921.

Pienso, repito, que ojalá esta novela se juzgue asimismo como un vasto homenaje literario y libertario a toda Irlanda, tierra de grandes escritores de la talla de George Bernard Shaw, William Butler Yeats, Oscar Wilde, James Joyce, Samuel Becket y John Millington Synge. Así, con esta última novela, se entenderá mejor que un libro puede ser también un ariete de la libertad, de la civilización, de la esperanzada comprensión humana, que, ojalá fuese posible, reinara alguna vez en todo el orbe.

\section{Carlos Eduardo Zavaleta $\dagger$}

Miembro del Consejo Directivo de la Academia Peruana de la Lengua. 